\title{
FAKTOR YANG BERPENGARUH TERHADAP MATERNAL - FETAL ATTACHMENT
}

\section{FACTORS AFFECTING MATERNAL - FETAL ATTACHMENT}

\author{
Evi Wahyuntari $1^{*}$, Tri Hapsari Listyaningrum² ${ }^{2}$ Siti Istiyati ${ }^{3}$

\begin{abstract}
${ }^{*}$ Universitas 'Aisyiyah Yogyakarta JI. Ringroad Barat No. 63 Mlangi Nogotirto Sleman email: evi.wahyuntari@unisayogya.ac.id, Indonesia

${ }^{2}$ Universitas 'Aisyiyah Yogyakarta Jl. Ringroad Barat No. 63 Mlangi Nogotirto Sleman email: trihapsari_listyaningrum@unisayogya.ac.id, Indonesia

Universitas 'Aisyiyah Yogyakarta Jl. Ringroad Barat No. 63 Mlangi Nogotirto Sleman email: bundaisty22@yahoo.com, Indonesia
\end{abstract}

\begin{abstract}
Background: Pregnancy, childbirth and postpartum is a transition period for a woman and is a complex life event that affects the biological, psychological, and social life experienced by the mother. Therefore the need to cultivate an inner bond between mother and baby or known as maternal fetal attachment (MFA).

Objective: Aim of this study was to find factors that influence MFA in pregnant women.

Methods: cross sectional study. The study was conducted at PKU Muhammadiyah Yogyakarta. Population is pregnant women routine ANC visits at the obstetric clinic. 100 respondents determined by the method of consecutive sampling. Inclusion criteria of pregnant women with a gestational age of 20-38 weeks, do not have high risk of pregnancy, no complications in pregnancy, and willing to become respondents. Exclusion criteria mothers who were not willing to become respondents. Data collection used a questionnaire consisting of basic data questionnaires for pregnant women, Socio demographic data, reproductive history, Pregnancy, PAI questionnaire, SSQ questionnaire.

Results: The planned pregnancy had an effect on the MFA with indigo $p<0.05$ OR 6, 44 which means that the planned pregnancy had an effect of 6.44 times on the MFA score. while age, education, parity, occupation has no effect on the MFA score

Conclusion: Planed pregnacy had an effect on MFA score in PKU Muhammadiyah Yogyakarta.
\end{abstract}

Keywords: Maternal Fetal Attachment, Pregnancy, Social Support.

\section{PENDAHULUAN}

Kehamilan, persalinan dan periode postpartum adalah masa transisi bagi seorang wanita dan merupakan peristiwa kehidupan yang komplek yang berdampak pada kehidupan biologis, psikologis, dan sosial yang dialami oleh ibu. Pada masa kehamilan merupakan masa dimana tubuh seorang ibu hamil mengalami perubahan fisik, dan perubahan psikologis akibat peningkatan hormon kehamilan. Adanya perubahan hormon tersebut mengakibatkan perubahan emosi yang cendrung berubah- ubah seperti merasa sedih, marah atau bahkan merasa sangat gembira. The American Congress of Obstetricians and Gynecologist (ACOG) mengungkapkan bahwa faktor psikososial berpengaruh terhadap kesehatan mental ibu. Oleh karena itu Perlunya menumbuhkan ikatan batin antara ibu dan bayi atau yang dikenal dengan maternal fetal attachment (MFA). ${ }^{1}$

MFA adalah adalah hubungan antara ibu dan janin pada masa kehamilan. Hal ini dapat dilihat sebagai keterlibatan ibu dalam menunjukan kasih sayang, perawatan dan komitmen untuk menjaga kesehatan 
janinnya. Hubungan antara ibu dan bayi disebutkan dalam teori attacment. ${ }^{1}$ Hubungan antara ibu dan bayi mulai berkembang sebelum bayi lahir, bahkan dimulai semenjak dalam kandungan. Diantara hubungan dengan individu, hubungan dengan ibu dan anak sangat penting. Muleer (1990) mendefinisikan bahwa kasih sayang pada masa kehamilan adalah hubungan yang unik antara ibu dan bayinya. ${ }^{2}$ Komponen keterikatan ibu dan janin meliputi keinginan mendapatkan kesehatan janin, interaksi dengan janin, merawat janin dan memenuhi

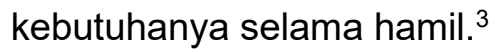

Selama kehamilan, ibu dan bayi hidup dalam simbiosis yang menguntungkan dan selama dalam masa kehamilan ibu berfikir mengenai bayinya, membayangkan dan berbicara dengan bayinya, apa yang ibu rasakan, hubungan ibu dan bayi tidak hanya mengenai nutrisi, tetapi dengan emosional. Ibu yang mempunyai MFA tinggi percaya bahwa ibu mampu membuat hubungan dengan janinya.

Penelitian terdahulu telah mengungkapkan hubungan MFA, hubungan dapat dipengaruhi oleh beberapa faktor, antara lain perkembangan kehamilan, gambaran tentang bayinya, gerakan janin, riwayat kehamilan, dukungan sosial, kecemasan ibu. Pada ibu dengan kehamilan risiko tinggi didapatkan faktor yang berhubungan dengan MFA antara lain kecemasan, multipara, kunjungan prenatal. ${ }^{4}$
MFA berpengaruh positif terhadap kehidupan ibu dan bayi. pengaruh yang ditimbulkan dari MFA berupa pengaruh sosial, psikologis, emosional dan perkembangan anak. Penelitian Gearity (2005) menjelaskan bahwa hubungan orang tua dan anak sebagai prototipe untuk hubungan masa depan anak, dengan suksesnya hubungan ini diprediksi untuk kesuksesan hubungan selanjutnya dan anak cenderung mempunyai rasa percaya diri yang besar serta menjadi mandiri dalam kehidupanya. ${ }^{5}$

MFA selama kehamilan akan berpengaruh terhadap perilaku bayi pada masa mendatang selama siklus kehidupanya dan meningkatkan rasa percaya diri. $^{6}$ Hubungan emosional antara ibu dan bayi mempunyai pengaruh pada sosial dan psikologis anak sepanjang daur kehidupanya. ${ }^{6}$

Penelitian ini bertujuan mengetahui faktor yang berhubungan dengan MFA, dengan mengetahui faktor tersebut dapat mengoptimalkan MFA sehingga melahirkan generasi penerus yang cerdas dan bermanfaat.

\section{BAHAN DAN CARA PENELITIAN}

Metode penelitian ini adalah cross sectional. Waktu penelitian dilaksanakan bulan Maret- Mei 2018 pada ibu hamil umur kehamilan 20-38 minggu yang melakukan kunjungan rutin kehamilan /antenatal care (ANC) di poli klinik RS PKU Muhammadiyah 
di Yogyakarta sejumlah 8.600 ibu hamil pada tahun 2016. Sampel dalam penelitian ditentukan menggunakan non probability sampling dengan metode consecutive sampling. Kriteria inklusi ibu hamil umur kehamilan 20-38 minggu, tidak termasuk risiko tinggi kehamilan, tidak ada komplikasi dalam kehamilan. Kriteria eksklusi dalam penelitian ini adalah ibu yang tidak bersedia menjadi responden. Besar sample dalam penelitian sebanyak 100 responden berdasarkan rumus Satroasmoro.

Responden yang memenuhi kriteria inklusi diberikan pernyataan persetujuan (informed consent) yang sebelumnya sudah diberikan penjelasan secara lisan mengenai maksud dan tujuan penelitian. Responden melengkapi kuesioner yang diberikan meliputi kuesioner data dasar umur, pendidikan, pekerjaan, dan status pernikahan), riwayat reproduksi (paritas, gravida, riwayat abortus), riwayat kehamilan (kehamilan terencana / diinginkan, umur kehamilan dan jumlah kunjungan antenatal). Kuesioner MFA di adop dari Suryaningsih ${ }^{7}$, dan kuesioner dukungan sosial. Responden yang mengalami kesulitan dalam mengisi kuesioner, maka peneliti membacakan kuesioner kemudian responden memilih jawaban sesuai kondisi dan peneliti menuliskan jawaban dalam lembar kuesioner
Analisis data menggunakan SPSS V.24 Data kategorik di gambarkan dengan jumlah dan frekuensi. Uji statistik yang digunakan adalah Chi Square test.

\section{HASIL DAN PEMBAHASAN}

Tabel 1. Karakteristik responden

\begin{tabular}{lcc}
\hline \multicolumn{1}{c}{ Karakteristik } & Jumlah & Prosentase \\
\hline MFA & & \\
$\quad$ Tinggi & 90 & 90,0 \\
$\quad$ Rendah & 10 & 10,0 \\
Pendidikan & & 77,0 \\
$\quad$ Tinggi & 77 & 23,0 \\
$\quad$ Rendah & 23 & 88 \\
Umur & & 12 \\
$\quad$ Tidak berisiko & 88 & \\
$\quad$ Berisiko & 12 & 46,0 \\
Paritas & & 54,0 \\
$\quad$ Primi & 46 & 65,0 \\
$\quad$ Multi & 54 & 35,0 \\
Pekerjaan & & \\
$\quad$ Bekerja & 65 & 77,0 \\
$\quad$ Tidak bekerja & 35 & 23,0 \\
Kehamilan \\
direncanakan
\end{tabular}

Sumber: data primer 2018

Berdasarkan hasil tabel 1 diketahui bahwa rata-rata skor MFA tinggi sebanyak 90 $(90 \%)$, dengan umur responden pada kategori umur tidak berisiko 88 (88\%), 77 (77\%) pendidikan tiggi, 54 (54\%) responden dengan multigravida, 65 (65\%) ibu bekerja, $65(65 \%)$ dengan kehamilan yang direncanakan. 
Tabel 2. Faktor MFA

\begin{tabular}{|c|c|c|c|c|c|c|c|}
\hline \multirow[t]{3}{*}{ Faktor } & \multicolumn{4}{|c|}{ Maternal Fetal Attachment (MFA) } & \multirow[t]{3}{*}{$p$ value } & \multirow[t]{3}{*}{ OR } & \multirow[t]{3}{*}{$\mathrm{Cl}$} \\
\hline & \multicolumn{2}{|c|}{ Tinggi } & \multicolumn{2}{|c|}{ Rendah } & & & \\
\hline & $\mathbf{N}$ & $\%$ & $\mathbf{N}$ & $\%$ & & & \\
\hline \multicolumn{8}{|l|}{ Umur } \\
\hline Tidak berisiko & 80 & 91 & 8 & 9 & 0,412 & 2,00 & $, 37-10,76$ \\
\hline Berisiko & 10 & 83 & 2 & 17 & & & \\
\hline \multicolumn{8}{|l|}{ Pendidikan } \\
\hline Tinggi & 69 & 89 & 8 & 10 & 1,00 & 0,82 & $0,16-4,17$ \\
\hline Rendah & 21 & 91 & 2 & 9 & & & \\
\hline \multicolumn{8}{|l|}{ Paritas } \\
\hline Primi & 42 & 91 & 4 & 9 & 0,75 & 1,31 & $0,34-4,97$ \\
\hline Multi & 48 & 88 & 6 & 11 & & & \\
\hline \multicolumn{8}{|l|}{ Pekerjaan } \\
\hline Bekerja & 59 & 91 & 6 & 9 & 0,74 & 1,27 & $0,33-4,84$ \\
\hline Tidak bekerja & 31 & 89 & 4 & 11 & & & \\
\hline \multicolumn{8}{|c|}{ Kehamilan direncanakan } \\
\hline Ya & 73 & 95 & 4 & 5 & 0,009 & 6,44 & $1,63-25,37$ \\
\hline Tidak & 17 & 74 & 6 & 26 & & & \\
\hline
\end{tabular}

Sumber: data primer 2018

Berdasarkan hasil penelitian yang dilakukan di RS PKU Muhammadiyah Yogyakarta didapatkan prevalensi MFA $90 \%$ Responden dalam penelitian adalah ibu hamil dengan usia kehamilan 28-38 minggu sebanyak 100 ibu hamil.

Hasil penelitian di dapatkan bahwa umur tidak hubungan dengan MFA dengan $p$ value $>0,05$, dapat diartikan bahwa umur tidak mempunyai hubungan yang signifikan dengan MFA, disimpulkan bahwa berapapun usia ibu saat hamil tidak berisiko terhadap keeratan hubungan ibu dan bayi. Penelitian ini didapatkan bahwa 8 responden $(80 \%)$ kelompok umur tidak berisiko dengan nilai MFA rendah dan sebanyak 2 responden $(20 \%)$ kelompok umur berisiko dengan nilai MFA tinggi. Penelitian yang dilakukan Mohamed et al (2017) didapatkan bahwa umur ibu berhubungan negatif dengan MFA, dikatakan bahwa dengan umur ibu yang semakin meningkat, maka level MFA semakin turun. ${ }^{8}$ Penelitian yang dilakukan oleh Lee umur merupakan faktor peningkatan MFA. Ibu yang berumur kurang dari 30 tahun didapatkan skore MFA lebih tinggi bila dibandingkan dengan ibu dengan umur lebih 30 tahun. $^{9}$

Hasil penelitian didapatkan pendidikan tidak berhubungan dengan MFA dengan $p$ value $>0,05$, sehingga dapat disimpulkan pendidikan tidak berpengaruh terhadap kejadian MFA. Penelitian ini didapatkan bahwa sebagian besar responden 69 (89\%) dengan pendidikan tinggi dan memiliki skor MFA tinggi dan hanya 2 (9\%) ibu dengan pendidikan rendah dan mempunyai skor MFA rendah.

Tingkat pendidikan menurut Mohamed et al (2017) tidak ada hubungan dengan skor MFA. ${ }^{8}$ Penelitian Abasi et al (2013) didapatkan bahwa pendidikan ibu terhadap MFA dapat meningkatkan kesehatan mental dan juga hubungan kasih sayang ibu dan 
bayi. ${ }^{10}$ Penelitian yang dilakukan oleh Abasi, et al dimana pada kelompok kasus diberikan pendidikan kesehatan perilaku MFA didapatkan hasil perbedaan yang bermakna pada kelompok kontrol. ${ }^{10}$ hal ini karena pendidikan kesehatan selama kehamilan berpengaruh positif terhadap kedekatan/kasih sayng ibu terhadap janin. Penelitian Kim and Cho's bahwa pendidikan kesehatan melalui promosi kesehtan seperti interaksi/komunikasi ibu dan janin dan rangsangan akan meningkatkan skor MFA. ${ }^{11}$

Sedangkan ibu dengan hubungan janin yang rendah akan mengakibatkan depresi dan kecemasan. Sitematik review yang dilakukan Iran didapatkan bahwa pendidikan orang tua berhubungan dengan peningkatan kasih sayang ibu dan janin. ${ }^{12}$ Pada masa kehamilan ibu akan memerankan 4 tugas penting dalam upaya menjadi seorang ibu menjalankan kehamilan dengan aman, penerimaan bayinya terhadap keluarga, mendapatkan dukungan komunikasi dengan bayi, oleh sebab itu pendidikan kesehatan terkait hubungan ibu dan janin akan meningkatkan kasih sayang dan kesadaran ibu dalam mengoptimalkan kehamilanya. ${ }^{12}$

Hasil penelitian di dapatkan paritas tidak berhubungan dengan MFA dengan $p$ value $>0,05$, yang diartikan bahwa paritas tidak berpengaruh terhadap MFA. Dalam penelitian ini didapatkan bahwa 54 (54\%) responden dengan multi para. Penelitian ini berbeda dengan penelitian terdahulu bahwa Ibu primipara mempunyai MFA lebih tinggi bila dibandingkan dengan multipara dengan $p$ $<0.04 .^{9}$ Sedangkan penelitian di Korea di dapatkan multipara merupakan faktor berpengaruh terhadap MFA dengan nilai $\mathrm{p}<$ 0,001. ${ }^{13}$ Mohamed et al (2017) dalam penelitianya menemukan bahwa terdapat hubungan yang signifikan antara jumlah kehamilan dengan level MFA, semakin banyak jumlah kehamilan maka skore MFA akan menurun. ${ }^{8}$

Hasil penelitian di dapatkan hubungan kehamilan direncanakan dengan MFA dengan $p$ value $<0,05$ dengan nilai OR 6,44 artinya bahwa kehamilan direncanakan berhubungan dengan MFA sebesar 6,44 kali. Kehamilan direncanakan akan memberikan hubungan yang positif. Dalam review salehi et al (2018) hubungan kehamilan direncanakan atau tidak masih menjadi perdebatan. ${ }^{12}$ Perbedaan tersebut dikarena perbedaan pemakaian alat ukur/ kuesioner yang digunakan. Dalam review tersebut didapatkan bahwa pada kehamilan yang tidak direncanakan akan meningatkan kecemasan dalam kehamilan dan menurunkan MFA. Dalam pengukuran MFA beberapa faktor yang konsisten berhubungan dengan MFA antara lain adalah kehamilan yang direncanakan, usia kehamilan dan gangguan mood ibu. ${ }^{14}$

\section{KESIMPULAN}

Berdasarkan hasil penelitian
didapatkan faktor yang berpengaruh
terhadap MFA adalah kehamilan yang


direncanakan, sedangkan umur, pendidikan, pekerjaan dan paritas tidak berpengaruh terhadap MFA. Saran: MFA dapat diterapkan di dalam pemberian konseling atau kelas ibu hamil sehingga dapat mengoptimalkan outcome kehamilan.

\section{TERIMA KASIH}

1. Terimakasih kepada Prof. $\mathrm{H}$ Mohammad Nasir, Ph.D selaku Kementerian Riset dan Teknologi Pendidikan Tinggi yang telah memberikan kesempatan pendanaan dalam penelitian ini.

2. LPPM Universitas 'Aisyiyah Yogyakarta (Ippm@unisayogya.ac.id)

\section{KEPUSTAKAAN}

1. Bowlby J. Attachment and Loss. Vol I. New York: Basic book; 1982.

2. Pellerone $M$, Miccichè $S$. Prenatal Attachment and Anxiety: Women Who Decide to Try in Vitro Fertilization and Women Who Procreate Naturally. Psychol Res. 2014;4(6):419-427.

3. Ohman S. Prenatal Examinations for down Syndrome and Possible Effects on Maternal- Fetal Attachment.; 2014.

4. Hee L, Young L. Factors Influencing Maternal-Fetal attachment among Pregnant Women. Adv Sci Technol Lett. 2015;16(3):2020-2028.

5. Malekpour M. Effects of Attachment on Early and Later Development. 2007;53(105):81-95.

6. Taixera M, Raimundo $F$, Antunes M. Relation between Maternal-Fetal Attachment and Gestational Age and
Parental Memories. J Nurs Ref. 2016;IV(8):85-92.

7. Suryaningsih $\mathrm{E}$. Indonesia Version of Prenatal Attachment Inventory(PAI):A Preliminary Study. National Taipei University Of Nursing and Health Sciences. 2015:3-5.

8. Mohamed N, Hassan M, Mohamed F, Elgwad A. Predictors of Maternal Fetal Attachment among Pregnant Women. J Nurs Heal Sci. 2017;6(1):95-106. doi:10.9790/1959-06010695106

9. Lee S, Lee S. Factors Influencing Maternal-Fetal attachment among Pregnant Women. J Korea Acad Coop Soc. 2015;16(3):2020-2028.

10. Abasi E, Tafazzoli $M$, Esmaily $H$, Hasanabadi $\mathrm{H}$. The effect of maternal - fetal attachment education on maternal mental health. Turkish J Med Sci. doi:10.3906/sag-1204-97

11. Kim J, Cho. The effect of mother-fetus interaction promotion program of talking and tactile stimulation on maternal-fetal attachment. orean $J$ Child Heal Nurs. 2004;10.

12. Salehi K, Kohan S, Taleghani F. Factors and Interventions Associated with Parental Attachment during Pregnancy in Iran: A Systematic Review. Int $J$ Pediatr. 2018;6(49):6823-6842. doi:10.22038/ijp.2017.26168.2232

13. Hee LS, Young LE. Factors Influencing Maternal-Fetal attachment in High-Risk Pregnancy. Adv Sci Technol Lett. 2015;104:38-42.

doi:http://dx.doi.org/10.14257/astl.2015 .104.09

14. Alhusen J. A literature Update on Maternal-Fetal Attachment. $J$ Obs Gynecol Neonatal Nurs. 2008;3:315328. doi:10.1111/j.1552- 